\title{
Exploring the Degree of Awareness of Teachers Regarding the Use of Multimodality and Its Influence on Online Teaching: A Case Study of Online Teaching before and during COVID-19 in Kuwait
}

\author{
Monirah Saad Alsalim ${ }^{1, *}$, Ayda A Al-Eidan ${ }^{1} \&$ Alaa Jaber Zeyab ${ }^{1}$ \\ ${ }^{1}$ Educational Technology Department, The Public Authority for Applied Education and \\ Training, Kuwait \\ *Corresponding author: Educational Technology Department, The Public Authority For \\ Applied Education and Training, Kuwait.E-mail: dr.monirah@gmail.com
}

Received: December 20, 2021 Accepted: January 23, 2022 Published: March 6, 2022

doi:10.5296/ije.v14i1.19345 URL: https://doi.org/10.5296/ije.v14i1.19345

\begin{abstract}
Teaching and learning took place differently before and during the COVID-19 pandemic. The pandemic changed the way people lead their lives - switching from traditional teaching (face-to-face) in a public setting to online teaching due to social distancing. The teaching system was forced to accommodate distance learning during COVID-19 to complete academic studies. As a result, some Gulf countries found it difficult to implement distance learning and blended learning due to a lack of infrastructure and other challenges and difficulties. In online teaching, to adequately meet the individual needs of students, effective communication and cooperation between the teacher and the student is required. Thus, this research seeks to determine the differences in teaching and learning during COVID-19. The major aim is to determine how teaching and learning occurred before COVID-19 and how effective they were during COVID-19. This paper studies teachers' use of multimodality in teaching and their perceptions, knowledge, and experiences before and during COVID-19. It also explores the implications and impact of using multimodality in teaching in line with technology before and during COVID-19. Additionally, it investigates the opinion of the teachers regarding their students' interpretation and interaction with multimodality.
\end{abstract}

Keywords: multimodality, COVID-19, technology, online teaching, face-to-face teaching 


\section{Introduction}

Multimodality is a research field that focuses on the communication and representation of multiple socially developed modes for meaning-making purposes (Lyons, 2016). These modes include layouts, colors, images, sounds, speeches, or gestures, and they are viewed as organized materials developed by societies to reflect their history, culture, tradition, and heritage. Therefore, they have a meaning-making that gets interpreted differently in various societies and social groups based on the way they perceive to shape and express power relations, ideologies, and values Adami, (2016). Multimodality combines different modes and semiotic materials such as actions and artifacts for use in communicative events like proxemics, gestures, layouts, writings, speeches, moving and still images, and texts (Adami, 2016).

Three primary assumptions underpin the study of multimodality. First, more than one mode is involved in communication. Second, selecting and configuring the various modes of communication in any given interaction builds the meaning of multimodality; and third, resources like signs, gestures, or languages that are used by those who are interacting, are shaped in a social way to create a shared cultural sense for the modes to make meaning. The foregoing makes multimodality highly dependent on context, thus making its meaning dependent on particular cultural and social frameworks that influence communication in different communities (Lyons, 2016).

In this study, the relationship between multimodality and technology is being highlighted because of the different technologies that have been introduced to enhance the expansion of media options through which humans can communicate effectively (O'Halloran \& Smith, 2012). Technology has also enhanced the ability for researchers to effectively study multimodality, which in turn has enhanced the perceptive ability of the human senses. COVID-19 has resulted in many businesses and services embracing the use of technology. The pandemic disrupted learning programs due to the protocols that were put into place by governments to mitigate the spread of the disease. Online teaching significantly replaced face-to-face learning (Zalat et al., 2021; Mu-Hua et al., 2020). The 'new normal' that has been triggered by COVID-19 calls for all stakeholders involved in education and training to embrace online delivery of classes, which brings the importance of adding multimodality into the mainstream. This study, therefore, examines the nexus between online teaching and multimodality from a teacher's perspective.

Papageorgiou \& Lameras (2017) have reported that before COVID-19, teachers' multimodality experiences entailed exploring concepts, enacting collaborative learning, and imparting information to the students. Face-to-face learning conveys knowledge to students through the interaction of speech and gestures (Fu and Zhou, 2019). It is an exemplified process of making meaning through the use of more teacher-directed modes like oral (voice), written (multimodal texts), and such visual representations as using the interactive whiteboard (Papageorgiou \& Lameras, 2017).

While a number of researchers have reported about their work toward establishing the nexus between teaching and multimodality, Yi \& Choi (2015); Ryu (2013); Jenny \& Swee-Kin 
(2016) a dearth of literature exists with regard to multimodality in the use of technology for teaching. Although some seminal work has been done in the area, more efforts are required to understand the relationship between technology and the delivery of effective learning outcomes Bezemer \& Kress (2015), especially when face-to-face learning is disrupted.

Teachers play a central role in education, making their preparation for effective technology-driven teaching vital (Boudersa, 2016). With the ever-evolving teaching landscape, teachers have been introduced to the use of such technology tools as laptops and mobile phones in their development and dissemination of educational content. Understanding how to use communication channels such as emails and school online teaching platforms is important for optimal effectiveness in their work (Selander \& Kress, 2017). Unfortunately, teacher-training programs rarely anticipate such advancements in technology that may have a profound bearing on the effectiveness of teaching by teachers (Muriel et al., 2018). This makes it difficult for teachers to deliver their curriculum effectively using technology as they are ill-prepared to complement auditory modes with gaze, gestures, etc. This is why enhancing teaching skills that use technology with multimodality is essential because it assists teachers to use multimodal communication better while teaching online.

In this regard, this study sought to contribute to the knowledge base regarding the use of technology with multimodality with the view of helping teachers enhance their use of multimodal communication with online teaching by drawing from invaluable lessons learned during the delivery of online teaching during the restrictions to face-to-face learning that were triggered by the COVID-19 pandemic. Precisely, the study sought to establish how teaching was delivered pre-COVID-19, during the COVID-19 periods, and examine the effectiveness of teaching during the COVID-19 period.

\subsection{Research objectives and focus}

This study sought to investigate the nexus between multimodality in line with technology and teacher online teaching. The specific objectives were to:

(a) Study teachers' use of multimodality in teaching as well as their awareness, perception, and experiences of multimodality before and during COVID-19.

(b) Examine the teachers' opinions about their students' perceptions and interactions with multimodality and the challenges of multimodality during COVID-19.

(c) Investigate how teachers use multimodality in teaching, in the context of technology, before and during the outbreak of COVID-19; and

(d) Explore the implications/obstacles the teachers faced during their use of technology in line with multimodality before and during the COVID-19 pandemic.

\subsection{Research Hypotheses}

As this research aims to examine different multimodal aspects for the teachers and learners to embrace online learning easily, the following hypotheses have been formulated that will be tested in this research.

[H1]: Creating awareness among the teachers regarding the use of multimodality in relation to communication, interpretation, modes, and meaning-making between themselves and 
students positively affects online learning behavior.

[H2]: The application of different multimodal approaches positively affects teachers and students to embrace the changes to teaching/learning brought by the pandemic.

\section{Literature Review}

Different researchers have defined multimodality in a variety of ways. Jewitt (2008) defines it as the construction of meaning through semiotic modes and resources, which implies that it entails using various semiotic modes to design a semiotic event or product. To Chomsky \& Halle (1968), multimodality represents a field of research that describes the meanings of verbal and non-verbal communications in a social context. Thompson (2017) posits that multimodality goes beyond verbal communication, making it not exclusively dependent on language. Thus, the path to meaning-making is unique to each student, as some students understand what is taught through the visual resources that teachers deliver through their body movements. In contrast, other students understand the same information just by listening to the teacher.

Edwards et al. (2014) investigated the relationship between technology and multiple communication modes like actions, space, gestures, images, and language among students studying mathematics and established that the use of each of the modes contributed differently to the students' effective understanding of the task at hand. They also reported that non-verbal modes such as gazes and gestures were as important as the language used in teaching during teaching. Technology contributed positively to learning outcomes by representing class materials in visual forms. Birchfield et al. (2008) studied the impact of multimodality on student learning outcomes and established that multimodal teaching enhanced students' performance, particularly in technology subjects. They concluded that using technology in the context of multimodality creates invaluable interactions between the students and the teachers that are driven by the students' familiarity with the technology being used.

Studies on how multimodality affects the structure and quality of classroom teaching have been an area of interest for many researchers. Barton \& Ryan (2013) investigated the association of multimodality in higher education and reported that multimodal communication helps teachers and students to reflect effectively and become creative. They argued that teachers' use of more than one teaching method, which the innovative use of technology could augment, enhance learning outcomes, and group work. Ryan et al. (2000) have supported this viewpoint by noting that the use of technology by teachers has the potential to make learning more accessible for students through resource-based learning.

A study by Davidsen \& Vanderlinde (2014), to establish how technology and multimodality shape the interaction and engagement between teachers and students, revealed that multimodality enables the discovery of how teachers can gradually incorporate technology in their teaching processes. 
Mishra et al. (2020) have reported that during the COVID-19 pandemic, technology played an important role in enhancing and supporting learning and teaching, especially when it was used in line with multimodality. They, however, posit that the way a teacher conducts the pedagogic process, educational software and technology-aided learning tools are very important to the delivery of the desired learning outcomes. Januszewski \& Molenda (2007) considered how educational technology enhances performance and learning from a teaching perspective, rather than just a tool, and reported that the parallel use of technological tools with such traditional teaching methods as lectures represents the typical integration of educational technology in pedagogy.

A number of studies have considered the implications and challenges of using technology with the hindsight of multimodality during the COVID-19 period. Al Fadda \& Liu (2020) investigated the effectiveness, challenges, and promises of the multimodal e-learning method and reported that e-learning positively impacts students' language skills. They established that teaching online improved teachers' creative skills, especially with the use of technological tools with multimodality. Lepp et al. (2021) investigated the factors that triggered teachers' decisions to teach online and how these decisions were reflected in the online teaching processes and established that the decisions were triggered by the availability of digital tools as well as the teachers' capability to purposefully use these tools within their home settings as well as the home settings of their students.

Lepp et al. (2021) and Mishra et al. (2020) investigated the challenges that were faced by teachers during their online teaching during the COVID-19 pandemic and reported that Internet challenges were the most pronounced. They reckoned that teachers innovated alternative means for their students who were affected by poor Internet connections so they could participate in online classes by including offline video lessons and PDF versions of the lessons.

Fadda and Liu (2020) have cited the need for more time to learn about e-Learning and prepare multimodal content and identifying that students had difficulties with group work as key challenges that came with COVID-19 pandemic's technology and multimodality teaching.

Mishra et al. (2020) studied the perception of teachers and students during the online teaching-learning process amidst the COVID-19 pandemic. They reported that the teachers and students used technological tools like YouTube, Google Meet, and Zoom to enhance teaching and learning during the pandemic period. They concluded that the ease of access to such online learning tools as e-libraries could significantly assist students in studying before class and during their free time (Amadioha \& Fiberesima, 2014). COVID-19 had made it important to gather more information regarding teachers' perceptions regarding technology and teaching, with emphasis on the use of multimodality, as well as their implications on teaching and learning, is required for informed improvements to online teaching encounters and programs, as well as student and teacher online experiences. This study sought to contribute to this need. 


\subsection{Conceptual Framework}

Appreciation of how COVID-19 exposed the inadequacy of teacher training in the area of technology and multimodality in teaching is very important. During the period of the pandemic, teachers were faced with the challenge of switching from face-to-face teaching to online teaching, yet they lacked training in online teaching (Espino-Diaz et al., 2020; Yenmez et al., 2016). Several authors reported the lack of teacher preparedness for online teaching prior to COVID-19 and the resulting impact on the teachers' delivery of the expected learning outcomes. Espino-Diaz et al. (2020) examined the impact of COVID-19 teachers' use of ICT and confirmed the existence of a gap in teacher training with respect to the use of ICT and its application in teaching.

König et al. (2020) explored the extent to which early career teachers mastered the core teaching challenges while maintaining social contact with the students during the COVID-19 period and reported that ICT tools, especially teacher education opportunities to acquire digital competence, affected the teachers' adaptation to online teaching during the pandemic. A study by Amhag et al. (2019) established that $37 \%$ of all teachers have a high-need perception while $50 \%$ have a medium-need perception regarding the training of teachers in the use of new technologies. Coincidentally, teachers that had low ICT competence also indicated high- to medium-need perceptions about ICT training for teachers.

Therefore, this study sought to answer the following key research questions:

(a) How was multimodality applied by teachers in teaching to create awareness, perception, and experiences before and during COVID-19?

(b) What were the teachers' opinions about their students' perceptions and interactions with multimodality and its challenges during the COVID-19 period?

(c) How did teachers use multimodality in teaching, within the context of technology, before and during the outbreak of COVID-19?

(d) Which implications/obstacles did the teachers face in their use of technology in line with multimodality before and during the COVID-19 pandemic?

\section{Method}

A qualitative research methodology was utilized in this study. Semi-structured interviews were administered to 5 teachers at an education college in Kuwait who were randomly selected and provided in-depth information to support the study. The reason behind choosing a small sample was that it allows in-depth analysis of a particular phenomenon in qualitative research. A great deal of information can be extracted regarding the research problem (Patton, 2002). Therefore, this research interviewed only five participants to gain a deep understanding of multimodality and its influence on the adoption of online learning. The interviews included conducting one session online with each of the interviewees through Microsoft Teams with the view to establishing how the teachers understood the aim of the interview, to get information regarding the teachers' use of multimodality in teaching, and to gauge their awareness, perception, the experience regarding multimodality before and during 
COVID-19. The participants, who were approached individually with twenty-three questions, had all voluntarily agreed to participate in the study. To ensure the anonymity of interviewees, pseudonyms have been used.

The interviews were conducted in Arabic because the researcher and the teachers are native Arabic speakers. This enabled the interviewees to freely express themselves and provide more details and explanations about their experiences and views. The interviews were recorded to keep the responses authentic, and the audio files were later transcribed. Multimodality and thematic analyses were used to analyze the data, and the findings compared with what existed in the prevailing literature.

Thematic analyses helped to draw upon the explicit and implicit meanings underpinning the obtained data and information (Braun \& Clarke, 2006). Requisite ethical arrangements were made prior to conducting the interviews with the participants.

\section{Results and Discussion}

\subsection{Multimodality Analysis}

This section presents the results of the analysis of the teachers' responses regarding their use of multimodality in teaching and their awareness, perception, and experiences of multimodality before and during the COVID-19 period (Perines, 2021). It also presents findings on the teachers' use of technology in line with multimodality before and during the COVID-19 period, as well as on the opinions of the teachers regarding their students' perceptions and interactions with multimodality and the challenges of using multimodality in teaching during the COVID-19 period.

The responses indicate that the teachers prefer face-to-face learning or a mixed method of teaching that combines both face-to-face and online teaching. Online teaching is considered important due to its use of different communication modes and interpretations while making use of educational technology.

\subsubsection{Language}

The participants indicated that their preferred mode of communication is the use of language. This mode involves the use of both written and spoken words. Four of the teachers viewed language as a 'very important as a mode of communication. The use of high pitch or raised/clear voices to pass a message across and get the students' attention forms part of this mode. Regarding the use of visual aids, three teachers indicated that they preferred the use of visual aids to initiate teaching at the beginning of their classes. This was the case both before and during the COVID-19 period, as it was effective in drawing the students' attention to the topic at hand. This agrees with findings from the study by Jewitt et al. (2001) that learning is realized through an interaction of visual, action-based, and verbal communication.

Moreover, all the participants preferred standing in front of their classes and moving around while teaching. This was the case before the COVID-19 outbreak, and it helped to ensure that 
each student heard what was being said. During face-to-face teaching before the COVID-19 outbreak, the participants indicated that they were able to see how attentive, engaged, focused, and interactive their students were while the class was going on (Pelochino, 2014). During the COVID-19 period, however, this was not possible with online teaching. All the participants indicated that they turned off their cameras during online lessons and used high-pitched voices to interact with the students. One of the participants indicated that she used Q\&A to get the students' attention during online classes. Other modes of communication tend to be irrelevant to students during online teaching, except for the voice, because the cameras were turned off.

A multimodal approach assumes that language, whether through speech or writing, is one of the available means of making meaning (Kress, 2012). Use of the gaze mode should be used to complement language.

\subsubsection{Gaze}

Four of the participants indicated a preference for the gaze mode, i.e., eye contact and facial expressions before COVID-19, because it helped them to determine if their students were attentive, distracted, or following the teachings. Using facial expressions helps the students recognize emotions. One of the participants indicated that she used a kind and sympathetic look while standing before students during face-to-face teaching sessions. Two of the participants said that they used eye contact while teaching face-to-face before COVID-19 as it helped them capture the students' attention (OECD, 2009). One of the participants said that she avoided making eye contact with any student during the face-to-face teachings before COVID-19 because some students became nervous when she did so, and she wanted all students to be comfortable when they were learning. All the participants affirmed the belief that using multi-modes improves the comfort of the students and increases their ability to receive information.

Regarding eye contact, while teaching online during COVID-19, two participants said that they usually turn on their cameras from time to time to check attendance, monitor the activities of the students in the class, and perform other follow-ups. They observed that this also helped the students to see that the teachers were in control. One of the participants observed that her relationship with her students significantly improved when online teaching began during COVID-19 because she turned off her camera. The participant noted that although she used gazing and eye contact while conducting face-to-face teachings, she believed that her students interpreted her facial expressions to imply that she was strict and not friendly.

\subsubsection{Gestures}

While different gestures may be used during teaching, the method and purpose in which they are used and their combination in parallel with other modes of communication is very important in teaching and learning. The application of multimodal communication in learning can be a teaching technique that combines several modes (Shalilah et al., 2018). All the participants indicated that before COVID-19, they preferred using body language while 
standing to get the students' attention. This correlates with reports that body movements allow messages to be conveyed more effectively, along with helping them to stay motivated (Bambaeeroo \& Shokpour, 2017). Three of the participants indicated that they used gestures and body language during the COVID-19 period because it helped to keep the students from becoming bored and distracted. One of the participants said that she just found herself using body language during online teaching because she was used to using it unintentionally during face-to-face teaching.

\subsubsection{Action/Object}

The participants indicated that before COVID-19 and during face-to-face teaching, they commonly used actions/objects to communicate were writing on the blackboard, interactive whiteboard, projector, and the use of several presentation tools like PowerPoint and other forms of software. During the COVID-19 period, they used newer actions and objects, including concept maps, interactive whiteboards, infographics, Google classroom, etc., in parallel with other communication modes such as voice, gaze, and gestures. This is because students understand and interpret a variety of topics when presented in both written and spoken language (Cutshall, 2012).

The participants reported that they stand while using the whiteboard in parallel with voice pitch, body posture, body language, gesture, and eye contact. They noted that the use of technology during both face-to-face and online teaching improved the interaction between the teachers and the students. This concurs with findings that students engage in conversations, provide and obtain information, express feelings and emotions, and exchange opinions when technology is used in teaching (Cutshall, 2012). The participants indicated that the use of technology created an atmosphere in which they communicated effectively with their students during online teaching. This could be attributed to the exponential rise in digital communication modes that enhanced multimodality (Bateman, 2017).

Some of the disadvantages of using technologies for online teaching during the pandemic that the participants highlighted were technical issues like speed, network connections, servers, and unfamiliarity with the use of the software features. They listed the advantages of using these technologies to include ease of communication with students and ease of content delivery. All the participants indicated that using the technical tools improved the students' attention span, created an environment for discussions, made teaching easier, and enhanced their relationship with the students.

The preceding multimodality analysis highlights the experiences, preferences, as well as the similarities and differences of the participants regarding their awareness and perception of the use of multimodality before and during COVID-19. All the participants indicated that as part of human nature, they naturally use multimodality because of how it had been inculcated into them through their culture, childhood, and previous experiences. Understanding how multimodality is associated with the cultural perceptions over the modes is therefore very important (Ademi, 2016). These representations show that community social interactions determine how modes are understood. They also affirm that new social and cultural identities can be established through the determinations and assumptions of the functions of 
multimodality (Bezemer \& Kress, 2008).

\subsection{Thematic Analysis}

Six thematic areas were analysed, namely;

(a) perceptions about multimodality,

(b) knowledge and use of multimodality before and during the COVID-19 pandemic,

(c) the preferred modes and multi-modes before and during COVID-19,

(d) impacts and challenges regarding multimodality before and during COVID-19,

(e) impact and challenges of using technology in line with multimodality in teaching, and

(f) teacher education and online teaching.

\subsubsection{Perceptions about Multimodality}

The perceptions about multimodality were considered in the light of the way the technologies were deployed and utilized for the design and delivery of learning content (Miller \& McVee, 2012). It was, therefore, more about the individual and the collaboration of the practice that is applied with technology, including the mechanisms that teachers incorporate to create meaning for students. Essentially, the emphasis on multimodality was action-situated, thus considering the social context as the major factor in meaning-making (Kress et al., 2001). Just as has been posited by Moreira \& Candau (2003), the perceptions that were elicited from the participants revealed that the act of meaning-making depends on the culture shared by a group.

Table 1 provides a snapshot of the responses that were provided by the participants regarding their knowledge about the use of multimodality before and during COVID-19.

From the above table, it can be established that all the participants used all the key communication modes before COVID-19. However, only three out of the five teachers used all the key communication modes during COVID-19. Furthermore, only two teachers stated that they used multimodality unintentionally when teaching, four mentioned that they acquired the use of multimodality from childhood, and three mentioned that they obtained multimodality from previous experience. However, none of the teachers were trained how to use multimodality. Finally, all the teachers stated that they used technology while teaching during COVID-19, and all the teachers agreed that using technology in line with multimodality eases the teaching process.

The participants indicated that they were not aware of the term multimodality or its usage before and during COVID-19. This implies that they were not taught about how to use multimodality in their training for their teaching profession. They are only aware of multimodality within the context of its use from their childhood and not during training and experiences while teaching. They revealed that their awareness and knowledge regarding the use of multimodality could be enhanced through self-learning/personal diligence because they unintentionally use it during teaching. 
Table 1. The Answers of the 5 Participants Regarding Their Knowledge and Use of Multimodality before and during COVID-19

\begin{tabular}{|c|c|c|c|c|c|}
\hline Participants & 1 & 2 & 3 & 4 & 5 \\
\hline $\begin{array}{l}\text { Knowledge of multi-modality as a term } \\
\text { by the teacher (known/unknown) }\end{array}$ & Unknown & Unknown & Unknown & Unknown & Unknown \\
\hline $\begin{array}{l}\text { Use of key communication modes } \\
\text { (language, gaze, gesture, and/or } \\
\text { action/object) during face-to-face } \\
\text { teaching before covid-19(Yes/No). }\end{array}$ & Yes & Yes & Yes & Yes & Yes \\
\hline $\begin{array}{l}\text { Use of key communication modes } \\
\text { (language, gaze, gesture, and/or } \\
\text { action/object) for online teaching during } \\
\text { covid-19(Yes/No). }\end{array}$ & $\begin{array}{l}\text { Not all } \\
\text { modes }\end{array}$ & $\begin{array}{c}\text { All } \\
\text { modes }\end{array}$ & $\begin{array}{c}\text { All } \\
\text { modes }\end{array}$ & $\begin{array}{l}\text { Not } \\
\text { all modes }\end{array}$ & $\begin{array}{c}\text { All } \\
\text { modes }\end{array}$ \\
\hline $\begin{array}{l}\text { Use of multimodality } \text { Un-intentional/ } \\
\text { by teachers while naturally } \\
\text { teaching (Yes/No). }\end{array}$ & Yes & No & No & Yes & Yes \\
\hline $\begin{array}{l}\text { Acquired from } \\
\text { childhood }\end{array}$ & Yes & Yes & Yes & Yes & No \\
\hline $\begin{array}{l}\text { Previous } \\
\text { experience }\end{array}$ & No & Yes & No & Yes & Yes \\
\hline Trained & No & No & No & No & No \\
\hline $\begin{array}{l}\text { Using technology while teaching } \\
\text { (Yes/No) }\end{array}$ & Yes & Yes & Yes & Yes & Yes \\
\hline $\begin{array}{l}\text { Does the use of technology in line with } \\
\text { multimodality ease the teaching } \\
\text { process? }\end{array}$ & Yes & Yes & Yes & Yes & Yes \\
\hline
\end{tabular}

\subsubsection{Preferred Modes and Multi-modes before COVID-19 (during face-to-face teaching)}

The findings of this study reveal that all the participants preferred and incorporated multiple modes during their teaching before COVID-19. The use of voice and standing before the class were the primary modes of communication before COVID-19. Regarding the combination modes with technology, they indicated that they combined body language, eye contact, body movement, and voice levelling/tone pitch with such technology tools as the interactive whiteboard, PowerPoint, and projector. These concur with those of researchers like Ryu \& Boggs (2016) and Vasudevan et al. (2010) that established growth in innovation towards the use of a combination of modes of communication before COVID-19, which means that the meaning-making results from or is made possible by people's usage of different communication modes to interpret a situation and negotiate social purposes (Nordby et al., 2017).

\subsubsection{Preferred Mode and Multi-mode when Teaching online during COVID-19}

This study found that the most preferred mode for teaching online during COVID-19 was the 
voice. All the participants indicated that they preferred to turn off their cameras during online teaching. The only mode that was used in parallel with voice was the action/object mode through the use of educational technology. Papageorgiou and Lameras (2017) also reported that the choice of modes used by teachers during the COVID-19 period included a combination of visual communications and written languages voice. The teachers' technology tools included Microsoft Word and Excel, Google sheet, email, virtual classroom, online tutorials, apps, and learning management systems like Microsoft Teams.

\subsubsection{Impacts and Challenges of Multimodality during COVID-19}

This study established that the impacts of multimodality during COVID-19 included improved attention, interaction, students' engagement, and the ability to reach a larger number of students. The number of students attending classes also increased during online teaching sessions. However, the disadvantage of the increased number of students was the inability to determine the effectiveness of knowledge acquisition. Teams software provided a tracking system that was advantageous to teachers because it supported them to focus on such other things as teaching and content creation while the tracking system checked and provided reports on students' attendance and participation at the end of each session.

Contrary to the experience of four of the participants, one respondent indicated that online teaching improved her relationship with her students. This finding confirms the results of studies that indicate that multimodality is not about the technology but is about the individual and the collaborative practices applied with the use of the technology (Papageorgiou \& Lameras, 2017).

4.2.5 Impact and Challenges of using Technology in Line with Multimodality in Teaching The participants indicated that they used technologies in their delivery of multimodality in teaching. The technologies enabled them to use such multimedia resources as online quizzes, recorded presentations, interactive images, and videos, which agrees with the findings by Philippe et al. (2020); and Sharples et al. (2016). The participants reported that technology options like Microsoft Teams helped them to improve their teaching as well as their evaluation of students during COVID-19, which concurs with the findings by Greenhow et al. (2009) that indicated how technologies assist both teachers and students in increasing their abilities for collective problem identification and solving, critical thinking, emotional intelligence, inter-and multi-disciplinary collaboration, leadership, and innovation in a participatory environment. The teachers also stressed that using technology in the delivery of multimodality offers multiple ways to represent teaching content through the use of multimedia besides improving the attention and participation of the students.

\subsubsection{Teacher Education and online Teaching}

The participants indicated that the university had trained them on using certain technological tools like Microsoft Teams for use in online teaching during COVID-19. However, they observed that this notwithstanding, they still encountered some challenges related to the technical management of the online teaching functionalities as well as network issues while using these tools during COVID-19. This shows the importance of continuous teacher 
training to help teachers enhance their competence in emerging areas. The principle of "teachers first" by Lankshear \& Knobel (2003) is suitable in this respect because it addresses the need for teachers to learn new technologies and how these technologies relate to language and literacy before the needs of the students are addressed.

\section{Conclusion}

This study sought to investigate teachers' use of multimodality in teaching and their perception, experience, awareness in the scope of multimodality and to investigate the implications and impact before (face-to-face teaching) and during COVID-19 (online teaching). Furthermore, it sought to explore teachers' use of educational technology together with multimodality in teaching and teachers' opinions regarding the interpretation and interaction of their students with the use of multimodality in teaching. Lastly, sought to investigate the implication of using technology in line with multimodality in teaching (online and face-to-face).

Findings reveal that teachers did not know multimodality before COVID-19. They, however, unintentionally used multimodality in teaching before COVID-19 (face-to-face teaching) through the parallel use of voice with other modes such as body movement and eye contact. The teachers' use of multimodality in teaching before COVID-19 without knowledge of the concept was due to their own/self-learning innovativeness. They indicated that they had used multimodality based on their childhood encounters, as a result of some training, and guided by their previous experience.

It also emerged that the many years of the teachers' teaching experience before COVID-19 had helped improve their multimodality use. An example of this was cited by one of the participants who said that while teaching online during COVID-19, the cameras were turned off; therefore, she used voice tone/leveling to get the students' attention. She also tracked students' participation after each teaching session using Microsoft Teams. This demonstrates that the use of multimodality before COVID-19 improved attention, interaction, and students' engagement.

Although the use of multimodality is widely expected to positively impact the teacher-student relationship, one of the participants provided a contrary opinion. She said that her students misunderstood her use of eye contact in parallel with voice before COVID-19. The students had interpreted it differently from the teacher's intentions. She went on to stress that her relationship with her students had improved through online teaching because the cameras were always switched off, and the students could no longer see her facial expressions.

Regarding the use of technology in line with multimodality in teaching before COVID-19, it was established that educational technology such as images, videos, and projectors helped improve the students' attention, interaction, and engagement. The participants stressed that a teachers' use of projectors (technology) together with language (voice leveling/tone) and gestures (body movement) improves teachers' interaction with the students, which made them view technology as part of the pedagogy and of teaching resources and technological tools as 
a means of facilitating learning and teaching as has been observed by Lepp et al. (2021). During COVID-19, technology played a very important role in teaching and learning, and technological tools helped teachers focus on teaching and preparing teaching materials.

However, the inadequacy of training on the use of multimodal resources and technological tools has resulted in several challenges being faced by teachers during the COVID-19 period. The main challenge relating to the use of technology in line with multimodality is the teachers' inexperience with using such technological tools as Microsoft Teams. Training on the use of Microsoft Teams for teaching as well as efforts to enhance the learning of new ways to deliver teaching using technologies, as happened over short periods of time during the COVID-19 period, should be emphasized. This is because, with practice, teachers can learn new technologies very well (Mishra et al., 2020).

Another challenge the teachers faced with regards to the use of technology related to technical issues like Internet speeds, network issues such as slow connections, and server issues like limited storage capacity and outdated computer systems. Therefore, these areas must be focused primitively for educational capacity enhancement because the use of technology in teaching will continue to form part of the 'new normal' triggered by COVID-19.

The COVID-19 pandemic has revealed the lack of technical training that is necessary for effective online teaching by teachers. It has also shed light on the poor quality of technological means and tools that are available to teachers for the effective delivery of online teaching. As has been suggested by Espino-Diaz et al. (2020), this study proposes that teacher training on the use and assimilation of educational technology and ICT in teaching be emphasized during teacher training. Such training should be provided through workshops, seminars, and lectures. Moreover, in-service follow-ups should be encouraged to periodically evaluate teachers' knowledge, competence, and proficiency in using technological tools.

The use of multimodality in teaching during COVID-19/online was found to be a big challenge for teachers. Although all the study participants indicated that they use different modes like voice, body language, gesture, and posture simultaneously when teaching online, they indicated that their students were unable to see the expression of the teachers because the cameras were turned off on both the teachers' and students' sides. This meant that the students only had access to one mode, the voice of the teacher. This was highlighted as a major challenge that made one of the participants complain about the effective use of multimodality while switching from one mode to another; despite all the efforts from the teacher, the students could not recognize the interaction associated with the teachers' use of multimodality. This notwithstanding, it is affirmed that different modes add more meaning and value to the learning process. This is because human beings have emotions that lead to enthusiasm regarding interactions in daily communications, whether face-to-face or virtually (through technological devices); hence, multimodality gives every person a unique identity.

This study has shown that there is generally a need to train teachers sufficiently on the use of multimodality in teaching. It includes how to use voice tone/leveling in parallel with eye contact and body movement as well as interactions in line with such technological resources 
as the interactive whiteboard and videos/apps to support meaning-making and improve the interpretation of the teaching process, especially in online teaching. The shortage of time, lack of resources, and insufficient training for effective online teaching made it difficult for teachers to cope with teaching during COVID-19 (online teaching).

The pandemic exposed the challenges and the importance of teacher awareness in the use of multimodality in teaching in line with technology. Teachers must understand the use of multimodality as well as educational technology tools in teaching through adequate access to appropriate training. Therefore, teachers need to provide necessary training and resources to support and enhance practical online teaching to deliver quality learning outcomes. Quality learning will, in turn, be underpinned by quality teaching that needs to be developed through the preparation of teachers on the use of up-to-date educational technology tools and sufficient training for the teachers to avoid future inadequacies in teaching as has been exposed by the pandemic.

Hence, it is recommended that teachers take urgent steps to receive training on the use of multimodal resources and educational technology tools and revisit how they teach under different circumstances/emergencies. This will help improve the teaching outcomes by providing long-term assistance to teachers, allowing them to act flexibly, be independent, and stay objective even during crises and emergencies.

\section{References}

Adami, E. (2016). Multimodality In: O. Garcìa, N. Flores and M. Spotti (Eds.), Oxford Handbook of Language and Society. Oxford: Oxford University Press. https://www.doi.org/10.1093/oxfordhb/9780190212896.013.23

Al Fadda, H., \& Liu, C. (2020). The Promises and Challenges of Multimodal Online Learning in Saudi Arabia. Revista Argentina De Clínica Psicológica, 29(4), 952-962.

Amadioha, S. W., \& Fiberesima, A. G. H. (2014). Teacher Education and Research Development in the 21st Century: Strategies, Implications for Education and Technological Advancement. Goldklass. International Journal of Scientific and Educational Research, 2(1), 211-218.

Amhag, L., Hellström, L., \& Stigmar, M. (2019). Teacher Educators' Use of Digital Tools and Needs for Digital Competence in Higher Education. J. Digit. Learn. Teach. Educ., 35, 203-220. http://dx.doi.org/10.1080/21532974.2019.1646169

Arroio, A., \& de Souza, D. D. D. (2012). Multimodality in Natural Science Education. Problems of Education in the 21st Century, 44, 5-9. https://dx.doi.org/10.33225/pec/12.44.05

Ashwin, P. (2014). Knowledge, curriculum and student undersanding. Higher Education, 67(2). https://doi.org/10.1007/s10734-014-9715-3

Assadi, N., Murad, T., \& Khalil, M. (2019). Training Teachers' Perspectives of the 
Effectiveness of the "Academy-Class" Training Model on Trainees' Professional Development. Theory and Practice in Language Studies, 9(2), 137-145. http://dx.doi.org/10.17507/tpls.0902.03

Bambaeeroo, F., \& Shokrpour, N. (2017). The impact of the teachers' non-verbal communication on success in teaching. Journal of Advanced Medical Educational Profession, 5(2), 51-59.

Barton, G., \& Ryan, M. (2013). Multimodal approaches to reflective teaching and assessment in higher education. Higher Education Research \& Development, 33(3), 409-424. https://doi.org/10.1080/07294360.2013.841650

Bateman, J. A., Wildfeuer, J., \& Hiippala, T., (2017). Multimodality: Foundations, Research and Analysis-A Problem-Oriented Introduction. DE Gruyter Mouton.

Bezemer, J. (2012, February 16). What is multimodality? Retrieved from https://mode.ioe.ac.uk/2012/02/16/what-is-multimodality/

Bezemer, J., \& Kress, G. (2008). Writing in Multimodal Texts: A Social Semiotic Account of Designs for Learning. Written Communication, 25(2), 166-195. https://doi.org/10.1177\%2F0741088307313177

Bezemer, J., \& Kress, G. (2015). Multimodality, Learning and Communication: A Social Semiotic Frame. London: Routledge.

Birchfield, D., Thornburg, H., Megowan-Romanowicz, M. C., Hatton, S., Mechtley, B., Dolgov, I., \& Burleson, W. (2008). Embodiment, multimodality, and composition: convergent themes across HCI and education for mixed-reality learning environments. Advances in Human-Computer Interaction. https://doi.org/10.1155/2008/874563

Boudersa, N. (2016). The importance of teachers' training programs and professional development in the Algerian educational context: Toward informed and effective teaching practices. Expériences Pédagogiques, 1(1), 1-14.

Braun, V., \& Clarke, V. (2006). Using thematic analysis in psychology. Qualitative Research in Psychology, 3(2), 77-101. https://doi.org/10.1191/1478088706qp063oa

Chomsky, N., \& Halle, M. (1968). The sound pattern of English. New York, Evanston and London: Harper \& Row.

Cutshall, S. (2012). More Than a Decade of Standards: Integrating "Communication" in Your Language Instruction. The Language Educator, 7(2), 34-37.

Davidsen, J., \& Vanderlinde, R. (2014). Researchers and teachers learning together and from each other using video-based multimodal analysis. British Journal of Educational Technology, 45(3), 451-460. https://doi.org/10.1111/bjet.12141

Edwards, L. D., Ferrara, F., \& Moore-Russo, D. (Eds.). (2014). Emerging perspectives on gesture and embodiment in mathematics. Charlotte, NC: Information Age Publishing. 
Espino-Díaz, L., Fernandez-Caminero, G., Hernandez-Lloret, C., Gonzalez-Gonzalez, H., \& Alvarez-Castillo, J. (2020). Analyzing the Impact of COVID-19 on Education Professionals. Toward a Paradigm Shift: ICT and Neuroeducation as a Binomial of Action. Sustainability, 12, 5646. https://doi.org/10.3390/su12145646

$\mathrm{Fu}, \mathrm{Z}$., \& Zhou, Y. (2019). Research on remote learning in multimodal interaction. International Association of Societies of Design Research Conference [Conference Presentation]. Manchester, United Kingdom. Retrieved from https://iasdr2019.org/uploads/files/Proceedings/le-f-1252-Fu-Z.pdf

Fuentes, A., Jesus L., \& Santiago, W. (2019). Analysis of the Digital Teaching Competence: Key Factor in the Performance of Active Pedagogies with Augmented Reality. Introducción. Reice Rev. Iberoam. Sobre Calid. Efic. Cambio Educ., 17, 27-42. https://doi.org/10.15366/reice2019.17.2.002

Greenhow, C., Robelia, B., \& Hughes, J. E. (2009). Learning, teaching, and scholarship in a digital age web 2.0 and classroom research: what path should we take now? Educational Researcher, 38(4), 246-259. https://doi.org/10.3102/0013189x09336671

Januszewski, A., \& Molenda, M. (Eds.). (2007). Educational technology: a definition with commentary. New York, NY and London: Routledge.

Jenny, M., \& Swee-Kin, L. (2016). Discursive constructions of teacher in an educational technology journal. Australasian Journal of Educational Technology , 32(5), https://doi.org/10.14742/ajet.2787

Jewitt, C. (2008). Multimodality and literacy in school classrooms. Review of Research in Education, 32(1), 241-267. https://doi.org/10.3102/0091732X07310586

Jewitt, C., Kress, G., Ogborn, J., \& Tsatsarelis, C. (2001). Exploring learning through visual, actional and linguistic communication: The multimodal environment of a science classroom. Educational Review, 53(1), 5-18. https://doi.org/10.1080/00131910123753

Kress, G. (2012). Multimodal discourse analysis from: The Routledge Handbook of Discourse Analysis. Routledge.

Lankshear, C., \& Knobel, M. (2003). New literacies: Changing knowledge and classroom learning. Buckingham, England: Open University Press.

Lepp, L., Aaviku, T., Leijen, 1., Pedaste, M., \& Saks, K. (2021). Teaching during COVID-19: The Decisions Made in Teaching. Educ. Sci., 11(47). https://doi.org/10.3390/educsci11020047

Miller, S. M., \& McVee, M. B. (2012). Multimodal composing in classrooms: Learning and teaching for the digital world. London: Routledge.

Mishra, L., Gupta, T., \& Shree, A. (2020). Online teaching-learning in higher education during lockdown period of COVID-19 pandemic. International Journal of Educational Research Open, 1, 100012. https://doi.org/10.1016/j.ijedro.2020.100012 
Moreira, A. F. B., \& Candau, V. M. (2003). Educação Escolar e Cultura(s): Construindo Caminhos (School education and culture(s): building paths). Revista Brasileira de Educação, 23, 156-168.

Mu-Hua, Z., Chein-Yuan, S., Yan, L., \& Yan-Yan, L. (2020). Factors affecting chinese university students' intention to continue using virtual and remote labs. Australasian Journal of Educational Technology, 36(2), 169-185. https://doi.org/10.14742/ajet.5939

Muriel, G., Davinia, H., \& Peter, B. (2018). Evaluation to support learning design: Lessons learned in a teacher training MOOC. Australasian Journal of Educational Technology, 34(2), https://doi.org/10.14742/ajet.3768.

Nordby, M., Knain, E., \& Jonsdottir, G. (2017). Vocational students' meaning-making in school science - negotiating authenticity through multimodal mobile learning. Nordina, 13(1), 52-65. https://doi.org/10.5617/nordina.2976

O'Halloran, K., \& Smith, B. A. (2012). Multimodality and Technology. The Encyclopedia of Applied Linguistics, Edited by Carol A. Chapelle. https://doi.org/10.1002/9781405198431.wbea10837

OECD. (2009). The Professional Development of Teachers. Creating Effective Teaching and Learning Environments: First Results from TALIS-ISBN 978-92-64-05605-3, 47-86. Retrieved from https://www.oecd.org/education/school/43023606.pdf

Papageorgiou, V., \& Lameras, P. (2017). Multimodal teaching and learning with the use of technology: meanings, practices and discourses. 14th International Conference on Cognition and Exploratory Learning in Digital Age (CELDA), 133-140. Retrieved from https://files.eric.ed.gov/fulltext/ED579485.pdf

Patton, M. Q. (2002). Qualitative research and evaluation method. London: Sage Publications.

Pelochino, M. (2014). Designing what's next in teachers' professional development. Retrieved from http://whiteboard.stanford.edu/blog/2014/03/27/designing-whats-next-in-teachers-profes sional-development

Perines, H. (2021). Educational Research Training in Teacher Training Programs: The Views of Future Teachers. International Education Studies, 14(1), 76-86. https://doi.org/10.5539/ies.v14n1p76

Philippe, S., Souchet, A. D., Lameras, P., Petridis, P., Caporal J., Coldeboeuf, G., \& Duzan, H. (2020). Multimodal teaching, learning and training in virtual reality: a review and case study. Virtual Reality \& Intelligent Hardware, 2(5), 421-442. https://doi.org/10.1016/j.vrih.2020.07.008

Ryan, S., Freeman, H., Scott, B., \& Patel, D. (2000). The virtual university: the internet and resource-based learning. New York, NY and London: Routledge. 
Ryu, J., \& Boggs, G. (2016). Teachers' Perceptions about Teaching Multimodal Composition: The Case Study of Korean English Teachers at Secondary Schools. English Language Teaching, 9(6), 52-60. http://dx.doi.org/10.5539/elt.v9n6p52

Shalilah, R., Rusijono, \& Mariono, A. (2018). The Role of Multimodal Communication in Language Learning: Making Meaning in Conventional Learning Spaces. Proceedings of the International Conference on Language Phenomena in Multimodal Communication (KLUA 2018), 228, 230-233. https://doi.org/10.2991/klua-18.2018.33

Sharples, M., de Rooc, R., \& Ferguson, R. (2016). Innovating pedagogy 2016: Open University innovation report 5. Milton Keynes: The Open University. Retrieved from http://oro.open.ac.uk/47961/

Thompson, V. (2017, September 26). Negative Reinforcement vs. Punishment in Elementary Schools. Retrieved from http://classroom.synonym.com/negative-reinforcement-vs-punishment-elementary-schoo 1s-7231.html

Vasudevan, L., Schultz, K., \& Bateman, J. (2010). Rethinking composing in a digital age: Authoring literate identities through multimodal storytelling. Written Communication, 27, 442-468. http://dx.doi.org/10.1177/0741088310378217

Yenmez, A. A., Ozpinar, I., \& Şahin, S. M. (2016). Teacher Training System and Process: Opinions of Teacher Candidates on Teacher Qualifications. Higher Education Studies, 6(3), 114-126. http://dx.doi.org/10.5539/hes.v6n3p114

Zalat, M., Hamed, M., \& Bolbol, S. (2021). The experiences, challenges, and acceptable of e-learning as a tool for teaching during the COVID-19 pandemic among university $\begin{array}{llll}\text { medical } & \text { staff. } & \text { PLoS }, & \text { 16(3), }\end{array}$ https://doi.org/10.1371/journal.pone.0248758.

\section{Copyright Disclaimer}

Copyright for this article is retained by the author(s), with first publication rights granted to the journal.

This is an open-access article distributed under the terms and conditions of the Creative Commons Attribution license (http://creativecommons.org/licenses/by/3.0/). 